\title{
R RÍTICA Y ASIMILACIÓN DE LA METRÓPOLIS MODERNA. REFLEXIONES EN TORNO AL TRIPLE EJE PARÍS-BERLÍN-NUEVA YORK A TRAVÉS DEL ARTE
}

JOSÉ MUÑOZ-ALBALADEJO

Instituto de Ciencias del Patrimonio. Consejo Superior de Investigaciones Científicas jose.munoz-albaladejo@incipit.csic.es

\begin{abstract}
Resumen: Este artículo pretende mostrar cómo el arte de finales del XIX y comienzos del XX trató de reflejar los cambios que se estaban produciendo en las ciudades tras la llegada de la Modernidad. Este recorrido se realizará a través de un triple eje que no es azaroso: París, Berlín y Nueva York. En París surgió la Metrópolis y dio comienzo el movimiento impresionista, y junto a él las primeras representaciones artísticas de las grandes urbes. En Berlín aparecen las primeras obras expresionistas, que traen consigo la crítica a esas grandes urbes. Y en EEUU esa visión de la ciudad pasa a asimilarse casi con resignación a través especialmente de las pinturas urbanas de las calles de Nueva York, que reflejan de fondo las teorías sociológicas hacia las que se encamina la recién fundada Escuela de Chicago. Toda esta serie de pinturas nos permitirán reflexionar sobre la relación entre las ciudades contemporáneas y las nuevas formas de socialización.
\end{abstract}

Palabras clave: Impresionismo / Expresionismo / Modernidad / Baudelaire / Simmel / Koolhaas.

\section{CRITICISM AND ASSIMILATION OF THE MODERN METROPOLIS. ARTISTIC REFLECTIONS AROUND THE TRIPLE AXIS PARIS-BERLIN-NEW YORK}

Abstract: This article shows how the art of the late 19th and early 20th centuries tried to reflect the changes that were taking place in the cities after the arrival of Modernity. This tour will take place through a triple axis that is not random: Paris, Berlin, and New York. In Paris appeared both the Metropolis and the Impressionist movement, and with them also appeared the first artistic representations of the large cities. In Berlin appeared the first Expressionist works, which bring with them the critique of these big cities. And in the U.S. that vision of the city was assimilated with resignation, especially by the urban paintings of the streets of New York, which reflect the sociological theories that were emerging in the School of Chicago. This series of paintings will allow us to reflect on the relationship between contemporary cities and new forms of socialization.

Key words: Impressionism / Expressionism / Modernity / Baudelaire / Simmel / Koolhaas.

\section{Introducción}

Todos los espacios que el ser humano construye tienen una base ideológica que lleva implícita unos valores u otros que posibilitan formas de vida muy diversas. De un tiempo a esta parte, cada vez son más las teorías que nos hablan de la mercantilización de los espacios y de la pérdida de identidad. Las relaciones interpersonales, antes tan reales, no son ahora más que relaciones abstractas que suceden en lugares genéricos, fríos.
Esto se refleja en el espacio que habitamos, en la ciudad, en sus calles y en nuestras viviendas, en los lugares de trabajo y en los de ocio. Antes esos espacios daban pie a la existencia de una comunidad real con relaciones reales. Ahora, en cambio, las ciudades se asimilan más a un conglomerado de construcciones en serie, viviendas tipo dirigidas a familias tipo que se asientan sobre ciudades tipo. Construcciones genéricas que crean individuos intercambiables cuyo lugar de origen no importa

* Fecha de recepción: 15 de octubre de 2017 / Fecha de aceptación: 18 de noviembre de 2018. 
en absoluto. "El turismo es independiente del destino", dirá Rem Koolhaas, ${ }^{1}$ y con razón: ya no importa la ciudad a la que viajes, porque la sensación no será distinta de una a otra. La arquitectura crea espacios iguales en ciudades a priori diferentes que provocan que dichas ciudades tiendan a la similitud. Así es como se produce la ciudad genérica de la que nos habla el propio Koolhaas, formada por multitud de esos no lugares que mencionaría el antropólogo Marc Augé.

"La ciudad irá en ti siempre", recitó una vez Kavafis, "otra no busques, no la hay". ${ }^{2}$ La ciudad siempre es la misma, sus calles son iguales, sus construcciones similares, sus valores inmutables. La imagen de aquel explorador romántico que busca incesantemente y en lugares remotos una naturaleza mística en la que hallar refugio es ya hoy algo lejano, oscuro y confuso, casi olvidado. El protagonista del poema de Kavafis huye de su pasado para buscar un futuro mejor, y ve en el cambio de lugar una puerta de salida a todos sus problemas. El narrador, sin embargo, le cierra esa puerta no porque no quiera dejarlo salir, sino porque ya no hay puerta, ha desaparecido.

La cuestión de la evolución de la ciudad y de las formas de socialización que en ella encontramos no es algo reciente. Ya en el siglo XIX el arte trató de reflejar esos cambios y luchar contra ellos, advertirnos de lo que estaba por llegar. Quizá la verdadera crítica del arte contra los nuevos cambios metropolitanos no se vio con claridad hasta la llegada del Expresionismo alemán, a comienzos del siglo $\mathrm{XX}$, aunque ya unos años antes el Impresionismo comenzó a mostrar el camino que las nuevas ciudades iban tomando. De eso, precisamente, trata este artículo: de cómo el arte ha sabido reflejar la evolución de las ciudades, que nos han transformado en individuos aislados cuyo contacto con el otro parece limitarse al principio de utilidad. Esto ocurre especialmente desde la aparición de las metrópolis, que tienen su origen en el París del Barón Haussmann pero que continúan apareciendo en el resto del mundo, con Berlín y Nueva York, con permiso de Chicago, como principales protagonistas de ese triple eje que se suele utilizar a la hora de hablar del nacimiento de la metrópolis. París porque supuso el inicio del cambio, no solo a nivel urbano sino a nivel social: a ella llegaron las modas y los nuevos sujetos de la mo- dernidad, que hicieron de esta ciudad la capital del siglo XIX, como diría Walter Benjamin. ${ }^{3}$ Berlín porque es el mejor ejemplo de cómo una ciudad puede pasar de ser una más a convertirse en una de las grandes metrópolis urbanas, repleta de construcciones rectilíneas y verticales capaces de alterar todo el espacio interno de una ciudad incapaz de reconocerse a sí misma. Y Nueva York porque es uno de los principales focos de recepción de inmigrantes dentro de EEUU y una de las ciudades que más comienzan a asimilar la deriva arquitectónica de las nuevas metrópolis.

Pero el arte no siempre será crítico con la llegada de la metrópolis. A veces solo reflejará los cambios, a veces solo meras escenas urbanas. A veces se resaltarán las cosas buenas de la modernidad, a veces los rincones más oscuros de las ciudades. Pero en ningún caso la llegada de la modernidad tiene que ir necesariamente ligada a una concepción negativa de la metrópolis. Dicha concepción vendrá después, cuando los cambios no vengan a integrarse en la ciudad, sino a sobreponerse a aquellos elementos que la dotan de identidad; tal vez no a destruirlos, pero sí a ocultarlos. Entonces el arte sí ha sido crítico. Los autores expresionistas alemanes, a comienzos del siglo $\mathrm{XX}$, ya resaltaron ese temor, ya supieron ver hacia dónde nos llevaba la ciudad genérica, influidos fuertemente por las teorías sociológicas de la época. De todo esto hablaremos a continuación.

\section{París, capital del siglo $\mathrm{XIX}$}

Allá por el año 1848, cuando el capitalismo comienza a asentar las bases ideológicas del nuevo mundo, empiezan a aparecer las primeras metrópolis, ciudades diferentes a las anteriores porque en ellas quedan reflejadas todas las transformaciones sociales que esa nueva ideología mundial pretende transmitir. La metrópolis es la metáfora de la vida moderna, el lugar al que la historia de Occidente nos ha conducido, un lugar en el que, como ya dijese el escritor francés Charles Baudelaire, todo se convierte en mercancía. Su inicio podemos fijarlo en la ciudad de París, pero su expansión ha sido grande y, sobre todo, rápida, tanto que hoy en día apenas quedan ya lugares que puedan mantenerse a salvo de su sombra, alejados de esta nueva forma de colonialismo propiciada por la llegada del capital y la economía de

${ }^{1}$ KOOLHAAS, Rem, 2011, p. 38.

2 Extracto del poema La ciudad, de Konstantino Kavafis. Traducción de José María Alvarez, en: KAVAFIS, Konstantino. Poesías completas. Madrid: Hiperión, 1981.

3 BENJAMIN, Walter, 1988. 
mercado. En aquel París decimonónico, una figura se alzó por encima del resto y escribió su nombre en los libros de Historia: la figura del Barón Haussmann, quien, bajo el dictamen del emperador $\mathrm{Na-}$ poleón III, hizo girar la capital francesa en torno a siete bulevares -algo que, según el teórico Marshall Berman, supondrá "la innovación urbanística más espectacular del siglo XIX y el paso decisivo hacia la modernización de la ciudad tradicional"- ${ }^{4}$ inmensas calles repletas de escaparates en los que mostrar las nuevas mercancías y que acaban uniéndose entre sí en el Arco de Triunfo. Son calles por las que caminará el flâneur, que representa al paseante tranquilo que busca cobijo entre la multitud, que experimenta la ciudad, que analiza la llegada de una modernidad que se asienta en la ciudad a ritmos descontrolados. El pintor Gustave Caillebotte fue uno de los primeros en captar la imagen de estos nuevos vagabundos de la modernidad. En Calle de París, día lluvioso (1877) se observa la figura del flâneur, vestido con levita y sombrero de copa, paseando por las calles de un París que crece a pasos agigantados.

Pero la visión de la época de aquel París no era negativa en absoluto. Si todo eso que hemos comentado en el párrafo anterior es lo que caracteriza a la moderna metrópolis parisina de mediados del siglo XIX, uno de los personajes que mejor supo captar todas esas características fue precisamente Charles Baudelaire. El París en el que Baudelaire vivió era un París de cambios, de contrastes y de sentimientos opuestos: por una parte, se anhela un pasado que ya no volverá; por otra, la nueva metrópoli te invita a sumergirte en las profundidades de un presente totalmente desconocido. El París de mediados del XIX es el lugar en el que el concepto de modernidad se redefine: "La modernidad es lo transitorio, lo fugitivo, lo contingente, la mitad del arte cuya otra mitad es lo eterno e inmutable". ${ }^{5}$ Y la misión del pintor de la vida moderna será la de extraer belleza de esta nueva época, pues lo bello tiene siempre una doble naturaleza: por una parte, tiene un elemento que es eterno, que siempre permanece; por otra, tiene un elemento relativo a cada época, a cada tiempo. Dentro de este nuevo escenario, el pintor de la vida moderna será aquel que pueda captar las modas, los momentos, los sentimientos, las emociones, las acciones, la vida en su más leve transformación, en su más pura esencia cambiante. Aquel capaz de bajar a las calles y pasear por ellas, sobre ellas, a través de ellas. Y Baudelaire le encomienda esa misión a su amigo Constantin Guys, al que definirá como "el pintor de la vida moderna". ${ }^{6}$

Quizá esta especie de nombramiento honorífico pudiese causar bastante sorpresa en la sociedad de la época, primero porque el enorme prestigio de Baudelaire, acostumbrado a mezclarse con la pléyade parisina, distaba mucho de la poca fama que poseía Guys, y segundo porque este último jamás había dado el salto a la primera línea del panorama artístico internacional. Hoy en día, de hecho, su nombre sigue siendo prácticamente una incógnita, apenas desvelada gracias a la trascendencia del trabajo de Baudelaire más que al suyo propio. Pero Baudelaire tenía sus motivos: la modernidad se caracteriza por la fugacidad, y Guys era el que mejor sabía captarla. La fugacidad de las modas, de los sentimientos, de las acciones. La fugacidad de los momentos que se olvidan para dar paso a otros nuevos momentos que mañana volverán a ser olvidados. La fugacidad es el emblema que porta la bandera capitalista que ha acabado alzándose sobre nuestras cabezas, gobernándonos a todos bajo ese yugo enmascarado que se oculta tras el cada vez más vacuo concepto de democracia. La sociedad occidental, gobernada por las lógicas capitalistas y en las que el punto de partida y de llegada es siempre el dinero, crea sobre sus miembros falsas necesidades que nos convierten en meros factores predispuestos a encajar en una fórmula ya establecida. Esa es la lógica económica del nuevo mundo. La ciudad actual se nutre de la producción del mercado, compuesta por consumidores desconocidos, anónimos, que se mueven salvajemente entre relaciones abstractas. Eso es lo que Guys captaba: imágenes de momentos, retratos de gentes sin rostro o de gentes con rostros iguales, dibujados con trazo decidido pero rápido, difuso, como si no hubiese que perder tiempo en ello. Lo que hoy es nuevo mañana será viejo y pasado será olvidado. Es la racionalidad del consumo feroz, que te incita a buscar sentimientos eternos en las modas más efímeras, resquicios de felicidad en las necesidades más banales, que son aquellas que han sido inventadas desde la nada. Por eso tal vez podamos hablar de la nueva metrópolis en los mismos términos que Kracauer hablaba de la Berlín de su tiempo, como si fuese la ciudad del olvido, un lugar en el que cualquier recuerdo, cualquier acontecimiento, cual-

\footnotetext{
${ }^{4}$ BERMAN, Marshall, 1989, p. 149.

${ }^{5}$ BAUDELAIRE, Charles, 1995, p. 92.

${ }^{6}$ BAUDELAIRE, Charles, 1995.
} 
quier anécdota, parece ser olvidada apenas un instante después de haber sucedido.

En su escrito, Baudelaire define a Guys como un hombre de mundo más que como un artista, un enamorado de la multitud anónima a la que el propio Guys pertenece, un verdadero contemplador de los paisajes urbanos, un pintor de lo cotidiano, del presente, el pintor idóneo para captar la caducidad de las nuevas costumbres en todo su ser. Es alguien capaz de ver la vida moderna de una forma distinta al resto, como nunca antes nadie la ha visto. Sus cuadros, pintados de memoria -sin modelos, sin bocetos previos-, intentan plasmar la modernidad y todo lo que la envuelve: la velocidad, el constante movimiento, el incesante cambio. Y la plasman precisamente porque Guys logra distanciarse de su obra y adoptar también la mirada del artista como flâneur. ${ }^{7}$ Para Baudelaire, solo Guys puede hacernos ver cada mínimo detalle que surge en esta sociedad de modas efímeras. Todo eso a pesar de que sus dibujos destaquen más las modas y los vestidos brillantes que la realidad del hombre de a pie, más el dandismo -"el último destello del heroísmo en las decadencias" ${ }^{8}$ que la vida del indigente, más la imagen que París pretende dar de puertas afuera que la imagen real, de puertas adentro, que viven aquellos que son más desafortunados. De hecho, los dibujos de Guys se centran más en aquella parte de la metrópoli que todo el mundo quiere ver y se olvidan, en cambio, del otro lado de la modernidad parisiense: el caos, la pobreza, el peligro, el terror. No captan el enfado del proletariado, no captan toda esa serie de elementos que acabarán dando lugar a las barricadas, a las revueltas, a la rebelión, a la miseria. Él, en el fondo, captaba las transformaciones, las calles, los cambios, al flâneur, al dandi; captaba, en definitiva, lo que París quería que fuese París. Lo que todos esperaban que fuese París.

En la segunda mitad del siglo XIX, junto al nacimiento del París del Barón Haussmann, nace un movimiento artístico que, aunque no podamos decir que sea revolucionario de puertas afuera del propio mundo del arte, sí que sentó un precedente en tanto que fue el primer gran movimiento artístico que supo hacerle frente a la Academia. Hablamos del Impresionismo, que a pesar de su escasa crítica social -esta se hará fuerte con la llegada del Expresionismo-, ya es capaz de reflejar, tal vez sin saberlo, a una sociedad que avanza a pasos agigantados hacia la homogeneidad más absoluta, más terrorífica. En el París de los bulevares, el arte no pudo dejar de lado el cambio. Estamos en una época en que todavía no ha aparecido la ciudad genérica, pero en la que se camina hacia ella. Constantin Guys supo captar los deseos cambiantes de los urbanitas, la fugacidad de los momentos, la banalidad de la vida. Esos rostros difusos, todos iguales, eran los propios de la gente de la nueva urbe, que mira más por sus propios intereses que por los colectivos. Que se olvida, sin saberlo, de que todos somos distintos pero estamos inmersos en redes de relaciones sociales que nos posicionan frente al mundo y nos definen. Los rostros que Guys dibujaba son aquellos de las personas que, poco a poco, se van individualizando y van destruyendo sus relaciones interpersonales, los rostros de las personas que tienden hacia la homogeneización. Son los rostros de los habitantes que pasean por esa nueva metrópolis que artistas como Caillebote han sabido plasmar tan bien, con sus amplias calles y sus escaparates siempre abiertos al público, dictándole a la gente la forma en que tienen que vestir, la comida que tienen que comer, el modo en el que han de vivir. Pero no es Guys el autor que hizo frente al arte de la época, sino los autores impresionistas. El Impresionismo se opuso al academicismo reinante, y entre esos nuevos artistas estaba Manet.

Incomprendido e incluso criticado en sus inicios, la pintura de Manet supone el punto de ruptura que la modernidad tanto reclamaba: él termina con el reinado de Delacroix y da inicio a un nuevo estilo, el Impresionismo, que sentará las bases para el nacimiento, en el futuro, del arte filosófico, aquel en el que el Espíritu hegeliano podrá aumentar el conocimiento de sí mismo: el arte de vanguardia. Baudelaire, sin embargo, que conocía la obra de Manet, jamás vio en él al "artista encargado de expresar 'I'héroisme de la vie moderne'", 9 algo que sí vieron teóricos posteriores como George Bataille, al señalar que Manet rompió con sus predecesores y "abrió la época en que vivimos, compenetrándose con el mundo de hoy, el nuestro; desentonando en el mundo en que vivía, al que escandalizó". ${ }^{10}$ Manet era una especie de rebelde sin causa, un provocador, y una de sus primeras provocaciones vino con la exposición en público

\footnotetext{
7 SMITH, Paul, 2006.

8 BAUDELAIRE, Charles, 1995, p. 116.

9 JARAUTA, Francisco, 2003, p. 13.

10 BATAILLE, Georges, 2003, p. 25.
} 
de La música en el Jardín de las Tullerías (1862), que se presentaba como una obra que rompía la forma, que cambiaba los colores, que difuminaba los trazos, que modificaba las miradas de los individuos que aparecían dibujados. En ella, Manet representa a un grupo de gente casi infinito que se sitúa en un jardín cuyo final no alcanzamos a ver. Todos ellos, envueltos en un tranquilo ambiente en el que la música de Offenbach suena de fondo, son producto de una nueva sociedad, producto de un nuevo estilo de vida, producto de una nueva moda. Las dos sillas de hierro, situadas en primera línea de acción, son el reflejo fiel de la era mercantilista. Lo que en el fondo se nos quiere decir es que la sociedad ha cambiado, y más allá del Jardín lo que está presente es la modernidad y la realidad baudeleriana, una realidad a la que pertenecen tanto los hombres de las Tullerías, vestidos todos iguales con chaqués y levitas negras, como Olimpia, la protagonista de una de las obras más rompedoras de Manet, una mujer que no es ya una diosa, sino una prostituta. Ambos, los hombres de las Tullerías y Olimpia, habitan el mismo mundo, el mundo que el arte de la época rechaza y que Manet se empeña en sacar a la luz. Esa otra cara de la modernidad que muchas veces las pinturas impresionistas esconden sale a la luz con la imagen de Olimpia, una prostituta que reclama su derecho no solo a estar, sino a ser dentro de una realidad en la que ella también tiene lugar, aunque se la ignore, del mismo modo que también parecen ignorarse las revueltas callejeras y las barricadas que de nuevo volvían a ser el pan de cada día en la capital francesa. Pero todo esto lo ignoran los visitantes del jardín, los dandis, los burgueses, y también lo ignorarán los asistentes a los bailes pintados por Renoir, personas que muestran al mundo la imagen de felicidad que la modernidad siempre lleva consigo para hacer creer que esa es la realidad, para hacerlo creer del mismo modo que sus defensores también lo creían.

Para Georges Bataille, la Olympia de Manet supone la negación del mundo pasado, "la negación del Olimpo, del poema y de las convenciones monumentales que se refieren a la realidad antigua de la Ciudad". ${ }^{11}$ Inspirada en la Venus de Urbino de Tiziano, que a su vez estaba inspirada en la Venus dormida de Giorgione, la Olympia de Manet es, sin embargo, un desnudo diferente a todos los que hasta entonces se habían realizado. Tras su exposición en 1863, Manet recibió un aluvión de críticas. Nadie parecía entender que lo que él pretendía hacer era recomponer "un nuevo orden de formas", 12 alejarse de un sistema y de una tradición artística que estaba llegando a su fin. A diferencia de la Venus de Cabanel, que, dibujada según los más estrictos cánones y reglas academicistas, representa un mundo que no existe, la Olympia de Manet, al contrario, es una Venus de carne y hueso. "Cuando miramos Olympia, lo que predomina es el sentimiento de una supresión, lo preciso de una fascinación en estado puro, la fascinación de la existencia que soberanamente, silenciosamente, ha cortado el lazo que la unía a las falacias que la elocuencia había creado". ${ }^{13} \mathrm{Si}$ la risa, según Bataille, es la más clara señal del rejuvenecimiento de la belleza, entonces la Olympia de Manet es justo lo que el mundo del arte necesita para rejuvenecerse, pues esta obra es "la primera obra maestra de la que se haya reído el público con una risa inmensa". ${ }^{14}$

Aunque podrían nombrarse muchas más obras capaces de plasmar la llegada de la Modernidad y las formas de vida que se daban en la metrópolis, tales como El viejo músico (1862), ${ }^{15}$ también de Manet, Place de la Concorde (1875) y El ajenjo (1876), de Degas, o La Place Clichy (1880), de Renoir, finalizaré mi viaje por las calles de París con una breve referencia a otra obra de Manet, El bar del FoliesBergère. Pintada en 1882, un año antes de su muerte, en ella su autor trató de plasmar la enfermiza pasión por la moda. En ella, Manet trata de simbolizar la banalidad del mundo moderno. En primer plano, detrás de una barra llena de boteIlas, aparece la protagonista: la joven Suzon, modelo que servía de inspiración al pintor, que es la encargada de atender a los clientes de un bar abarrotado de personas vestidas todas ellas con ropas similares, ropas que acentúan el anonimato propio de la sociedad metropolitana, ropas que, vistas to-

\footnotetext{
11 BATAILLE, Georges, 2003, p. 69. A la Olympia de Manet le dedica T. J. Clark un capítulo completo, titulado Olympia's Choi$c e$, en su libro The painting of modern life. Paris in the art of Manet and his follower (Nueva Jersey: Princeton University Press, 1984, pp. 79-147).

12 BATAILLE, Georges, 2003, p. 42.

13 BATAILLE, Georges, 2003, p. 65.

14 BATAILLE, Georges, 2003, p. 26.

${ }^{15}$ Sobre esta obra y su relación con el tema tratado en este artículo, Paul Smith apunta que en ella "reaparece el bebedor de absenta, junto con algunos artistas y actores ambulantes que han sido echados de la ciudad por las nuevas y severas condiciones para obtener permisos que Haussmann había impuesto a estos tipos sociales" (SMITH, Paul, 2006, p. 45).
} 
das ellas en conjunto, tan iguales, tan carentes de personalidad, forman una imagen que llega casi hasta a rozar el ridículo. "Nadie como ellos representa (mejor) el París de aquellos años". ${ }^{16}$ Agotada, con la mirada perdida y llena de fatiga, Suzon atiende a un hombre que intenta seducirla, un hombre no diferente a cualquier otro hombre dentro de un París que, inmerso ya en plena modernidad, se ha convertido en una ciudad llena de apariencias, llena de individuos desconocidos, sin rostros ni personalidades; en una ciudad en la que, por encima de todo, domina la mercancía.

\section{Berlín, la ciudad del olvido}

A la hora de captar la realidad, el impresionista buscaba, según palabras de Siegfried Kracauer, "atrapar sus momentos singulares y materializarlos puramente", pero esa realidad se mantenía fija, como un hecho que no puede ser modificado, que no puede ser atravesado ni criticado. El expresionista, en cambio, es alguien que ha logrado "abrir una brecha" en esa idea, "cumpliendo en los dominios del arte lo que las grandes revoluciones sociales del presente se plantean como tarea en los dominios de la vida real: la aniquilación de los poderes existenciales hasta ahora vigentes", ${ }^{17}$ alzándose en contra de la realidad que le rodea. Mientras en la pintura impresionista se busca una representación del mundo exterior, "presente a los sentidos", en el expresionismo esa mirada se vuelve hacia dentro, hacia la experiencia interior, psicológica. ${ }^{18}$ El expresionista es, ante todo, un crítico, alguien que trata de negar la realidad, eliminarla y hacer que su yo interior se exprese, salga a la luz y trate de autoafirmarse por encima de una realidad mecanizada que ha difuminado las relaciones sociales, ha absorbido el alma de los seres humanos y ha economizado el mundo. "Ya no vivimos, solo somos vívidos", dirá Hermann Bahr, para después añadir que "ya no tenemos libertad, ya no nos está permitido tomar decisiones, estamos perdidos, el hombre está inánime, la naturaleza, deshumanizada. [...] Nunca en el mundo hubo un silencio sepulcral así. Nunca el hombre fue tan pequeño. Nunca tuvo tanto miedo. Nunca la alegría estuvo tan lejos y la libertad tan muerta". ${ }^{19}$ El olor a putrefacción social es tan grande, que el expresionista lo que intenta es tapar dicho olor, "derrotar a una cotidianidad vacía, insignificante, frustrante" ${ }^{20}$ sentar las bases para que el alma de cada individuo escape de la cárcel de la sobremodernidad y el mecanicismo. Si París fue el inicio, Berlín fue su continuación, porque ningún otro lugar del mundo representa mejor que ella lo que las nuevas áreas metropolitanas deben ser. De hecho, el rápido crecimiento que sufrió, tanto a nivel demográfico ${ }^{21}$ como arquitectónico, desde que fuese nombrada capital del Reich en enero de 1871 , suscitó opiniones muy diversas entre los teóricos del momento. Incluso llegó a ser calificada como una ciudad demasiado moderna, hasta el punto de que en ella ya no parecía tener lugar la figura del flâneur, tan importante en la transformación parisina.

Este panorama no pasó desapercibido para la sociología alemana de la época, que no pudo ignorar la más rápida transformación que jamás haya sufrido una metrópolis: el incremento del tráfico, el desarrollo arquitectónico, la llegada masiva de inmigrantes, la urbanización descontrolada, el aumento de los conflictos sociales y políticos. Todo eso hizo de Berlín, como ya señaló Siegfried Kracauer, la ciudad del olvido. Las interpretaciones sociológicas de toda esta serie de hechos fueron de lo más diversas, desde aquellas que evocaban con nostalgia el mito del buen pasado y trataban de realzar el valor de las relaciones "reales" de las antiguas provincias frente a la abstracción metropolitana, hasta aquellas otras que ven en el nuevo Berlín la posibilidad de reorientar las expresiones artísticas, fortalecer las relaciones comunitarias y aumentar la libertad de los individuos. Y quizá a medio camino entre ambas esté la teoría de Georg Simmel, una teoría que tiene como objetivo, "sin caer en el lamento nostálgico, el examen cuidadoso de los fenómenos que constelan la existencia conflictiva y contradictoria en los lugares de la contemporaneidad".22 Muy influido por las ideas expuestas por Baudelaire, Georg Simmel decide hacer suya la tesis de que todo se convierte

16 JARAUTA, Francisco, 2003, p. 19.

17 KRACAUER, Siegfried, 2006, pp. 51-52.

18 RANNELS, Edward W., 1945, p. 13.

19 BAHR, Hermann, 1998, pp. 103-104.

20 PIZZA, Antonio; PLA, Maurici, 2002, p. 116.

${ }^{21}$ Berlín pasó de tener apenas 201.000 habitantes en 1819 a tener 2.700 .000 en el año 1900, tal y como recogen PIZZA, Antonio y PLA, Maurici, 2002, p. 102.

22 PIZZA, Antonio; PLA, Maurici, 2002, p. 112. 
en mercancía, tesis sobre la que se asentará la crisis de la cultura moderna.

Para Simmel, el punto de partida es el dinero, que es el que lo mueve todo dentro de la nueva metrópolis; así lo expresa al afirmar que "la moderna gran ciudad se nutre casi por completo de la producción para el mercado, esto es, para consumidores completamente desconocidos, que nunca entran en la esfera de acción del auténtico productor". ${ }^{23}$ Ya lo señalábamos antes: la ciudad moderna no está formada por relaciones reales, sino abstractas. Eso es lo que ocurre con las relaciones que apunta Simmel, basadas únicamente en las transacciones económicas. El nuevo sujeto urbano es producto de un modelo de mercado y de producción que apenas deja lugar para las relaciones sociales. El urbanita se guía por la puntualidad y el cálculo y basa sus relaciones en ellos, hasta el punto de que "si todos los relojes de Berlín comenzaran repentinamente a marchar mal en distintas direcciones, aunque solo fuera por el espacio de una hora, todo su tráfico vital económico y de otro tipo se perturbaría por largo tiempo". ${ }^{24}$ Los efectos que todo esto produce en la psicología del nuevo sujeto de ciudad son bien claros: incremento de la nerviosidad, exclusión de cualquier tipo de irracionalidad y, sobre todo, aumento de la desconfianza, de la indolencia y de la insensibilidad.

Al mismo tiempo, sin embargo, la inserción en la metrópoli hace que el intelecto domine frente al sentimiento, que los individuos sientan que aumentan sus experiencias de libertad, que se creen nuevos comportamientos. Pero a pesar de que este sea el espacio en el que se desarrolle el intelecto, también es el espacio en el que se corre el riesgo de que dicho intelecto quede anulado, algo que sucede cuando nos dejamos atrapar por la masa. En el fondo, lo que ocurre es que "las más refinadas propiedades anímicas del hombre singular deben ser abandonadas" 25 cuando este entra en la vida social, y eso puede llevar al abandono de la individualidad en favor de la masa, una ma- sa que transforma la esencia de los individuos que la conforman. Esa misma masa que Georg Grosz tan bien supo captar en muchas de sus obras. ${ }^{26}$ Una masa que, sin saberlo, ha quedado atrapada en una metrópolis en la que campea, aunque con un disfraz distinto, la misma violencia de la Gran Guerra, aquella que ha aniquilado nuestras más profundas convicciones morales.

En la ciudad moderna se escenifica el drama de la individualidad, la absorción de los hombres por la masa, la desconfiguración de unos rostros que tienden a ser cada vez más iguales, más uniformes. Indistinguibles los unos de los otros. Si antes decíamos que las personas que habitan los cuadros parisienses son las que reflejaba Guys, ahora las que viven en las ciudades expresionistas son las que dibuja George Grosz. ${ }^{27}$ En sus cuadros, lo que Grosz nos muestra son personas con rostros vacíos, articuladas como si fuesen autómatas, ubicadas en paisajes urbanos que tienden a la verticalidad, plagados de edificios altos y rectilíneos. Lugares en los que el bar de la esquina, aquel que plasmó Edward Hopper en Nighthawks, no es más que un bar cualquiera en una esquina cualquiera de una ciudad cualquiera del mundo, porque la ciudad genérica, aquella que augura el expresionismo, es intercambiable y carece de personalidad. Los cuadros de Grosz vaticinan la ciudad genérica del futuro, aquella a la que tanto temen los expresionistas y que tan bien se plasma en la película Metrópolis (1927), de Fritz Lang, o, de un modo más "realista", en el documental Berlín, sinfonía de una ciudad (1927), dirigido por Walter Ruttmann. La ciudad genérica, término acuñado por el arquitecto Rem Koolhaas para hablar de esa ciudad sobremoderna -como diría el antropólogo Marc Augé ${ }^{28}$ para referirse a aquella otra modernidad que viene después de la baudeleriana y que ya se describe en términos puramente negativos- que está liberada "del corsé de la identidad", ${ }^{29}$ es aquella que carece de historia y de personalidad. Es la ciudad por la que pasean los transeúntes anónimos que no se relacionan

\footnotetext{
23 SIMMEL, Georg, 1986, p. 249.

24 SIMMEL, Georg, 1986, p. 250.

25 KRACAUER, Siegried, 2006, p. 85.

26 Sobre Grosz y el concepto de masa, véase LESMES GONZÁLEZ, Daniel, 2006.

27 En realidad, a George Grosz no se le puede calificar únicamente como autor expresionista. Aunque es cierto que vivió durante la gran época del expresionismo alemán, y que estuvo muy influenciado por este movimiento, sus obras suelen ser enmarcadas, sobre todo, dentro de la Nueva Objetividad. La crítica social que hace sobre la masa, sin embargo, encaja a la perfección con la crítica expresionista a las grandes urbes. Sobre la renuncia de Grosz al expresionismo y su acercamiento a la Nueva Objetividad, véase, de nuevo, LESMES GONZÁLEZ, Daniel, 2006.

28 AUGÉ, Marc, 2005.

29 KOOLHAAS, Rem, 2011, p. 12.
} 
entre sí, que consumen por el mero hecho de consumir y que invierten su tiempo en lo que el poder hegemónico les dice que lo inviertan. En las nuevas modas, por ejemplo. La ciudad genérica es la ciudad fácil, superficial, que se actualiza a diario, que destruye lo que no es útil y que acoge con los brazos abiertos cualquier novedad que parezca cumplir una función. Son ciudades fundadas sobre la tesis de que todo se convierte en mercancía, de que todo es mercancía, espacios que parecen necesitar renovarse constantemente para tratar de mantener su identidad. En este sentido, podemos ver cómo el análisis de Simmel tiene un lado negativo que de inmediato se detecta: en él se pretende dar cuenta de la frialdad e indiferencia que forjan la personalidad de los urbanitas. No es de extrañar que Simmel hable de la antipatía como una de las "más elementales formas de socialización", además de decir de ella que es la causante de "las distancias y desviaciones sin las que no podría ser llevado a cabo este tipo de vida". ${ }^{30}$

Ante este panorama tan desolador se alzaron los autores expresionistas, tratando de hacer ver a los individuos que son ellos los que tienen que hacerse dueños de sus propios pensamientos, de su propia vida. De lo que se trata es "de que el hombre quiera reencontrarse a sí mismo", ${ }^{31}$ algo que solo podrá conseguir si lo que se hace es primar la expresión de los sentimientos por encima de la realidad objetiva, cuyo valor parece haber decaído hasta los más bajos fondos. Al dar primacía a la expresión de los sentimientos la realidad se acaba mostrando tal y como es: "una engañosa vivencia sombría, un caos sin alma, sin sentido". ${ }^{32}$ La serie de pinturas de Ludwig Meidner que llevan por título Paisaje apocalíptico (1913) pueden tal vez mostrarnos esa nueva realidad metropolitana, aunque no hay que olvidar el contexto en el que vieron la luz: la época inmediatamente anterior al estallido de la Gran Guerra. En esos cuadros se muestra el temor de unas personas, casi siempre en primer plano, que huyen despavoridas de la violencia de una ciudad que les es hostil, violencia que el autor trata de plasmar a través de la representación de unas ciudades con formas distorsionadas envueltas en llamas, de tal manera que el paisaje urbano parece asimilarse a cualquier representación popular de lo que podría ser el Infierno. La violencia hacia la que parece aproxi- marse el mundo, con Alemania como principal protagonista, sin duda influyó en esas representaciones hostiles de la vida moderna, aunque teóricos como Antonio Pizza y Maurici Pla insisten en que las llamas de la ciudad representan "la infranqueable distancia entre el sujeto y la manifestación catastrófica de su degradación... aquel universo urbano que exterioriza una fundamental hostilidad con respecto al hombre". ${ }^{33}$

En este nuevo arte que es el Expresionismo, todo queda trastocado: espacio, color y forma ya apenas nos son familiares. Lo que se muestra es el alma del autor, y es a través de la representación de los difusos límites del alma como el expresionismo trata de hacernos ver el triunfo de esta sobre la realidad, creando un estilo de arte nuevo en el que ya nada es lo que parece. Se nos muestra la podredumbre interior a la que nos conduce la ciudad genérica y se reclama, urgentemente, la creación de un mundo nuevo, más aún después de los desastres de la guerra: tras ella, es el individuo el que empieza a acaparar toda su atención, un individuo que, impotente, ha sido arrojado a un mundo infernal y repleto de violencia. Es lo que Max Beckman refleja en muchos de los cuadros y litografías que crea durante y después de los años de la Gran Guerra, y que tienen quizá su máxima representación en la obra titulada La noche, pintada entre agosto de 1918 y marzo de 1919, y en la que se muestra cómo la violencia y el caos con los que el individuo tiene que convivir en la calle es capaz de penetrar en las casas, a través de la representación de una familia que está siendo torturada por varios maleantes que han ocupado su espacio más íntimo para tratar de exponer al espectador, tal vez, la miseria de la existencia humana.

Otro autor contemporáneo a Grosz y a Beckman, a menudo comparado con el primero $y$, como el segundo, fuertemente influido por la guerra, fue Otto Dix, al que se le suele incluir tanto dentro del Expresionismo como del movimiento de la Nueva Objetividad. Igual que Grosz, Dix reflejó el tema de la ciudad en sus obras, aunque con la diferencia de que él se preocupaba, sobre todo, por mostrar el dolor y la desesperación de las víctimas, mientras que las pretensiones de Grosz iban más encaminadas a la agitación política. Dix intentó apartarse de la acción y limitarse a dar testimonio de sus expe-

\footnotetext{
30 SIMMEL, Georg, 1986, p. 254.

31 BAHR, Hermann, 1998, p. 103.

32 KRACAUER, Siegfried, 2006, p. 54.

33 PIZZA, Antonio; PLA, Maurici, 2002, p. 120.
} 
riencias, especialmente aquellas vividas en la Gran Guerra, en la que se alistó voluntariamente y que marcaría un antes y un después en su obra. ${ }^{34}$ Desde entonces, se dedicaría a tratar de mostrar el horror de la misma aunque, como él mismo apuntaba, de una forma en cierto modo objetiva, limitándose a dar testimonio de ella. Pero pintar sin una toma de conciencia personal es tan complicado que realmente no puede decirse que sus obras estuviesen exentas de juicios de valor, pues en ellas era evidente una clara toma de conciencia en favor de una posición contraria a la guerra.

Por otra parte, el enorme desarrollo urbanístico y el incremento de la verticalidad de las construcciones tampoco pasaron desapercibidos para el resto de autores expresionistas. Un ejemplo claro se encuentra en el movimiento Die Brücke (El puente), cuyos autores hicieron del desnudo un motivo central en sus representaciones artísticas, hecho que sugiere "su conexión con la ola de iniciativas reformistas anti-urbanas que estaba brotando en Alemania en aquellos años". ${ }^{35}$ Entre los integrantes de este movimiento se encuentra Ernst Ludwig Kirchner, que plasmó estas transformaciones en unas pinturas que tratan de acercarnos a la realidad metropolitana mediante la exageración de unas formas que se hacen cada vez más geométricas. Así, se abandona la preocupación por el volumen y la perspectiva, que se hace más diagonal y rompe con cualquier resquicio de estabilidad. Ahora la ciudad hiere; sus edificios, antes tan seguros, se alzan violentamente ante los ojos de los espectadores. La poca naturalidad de los colores, cercanos a la irrealidad, tampoco ayuda a despertar nuestra simpatía por las nuevas formas urbanas. Esa arquitectura vertical, a su vez, se refleja también en la representación de unos personajes con formas alargadas que suelen ocupar siempre los primeros planos del cuadro y que forman parte del mismo paisaje urbano, se entremezclan con él y acaban dando la impresión de que la vida en la gran metrópolis que es Berlín, muy diferente a su Dresde natal, es frenética, rápida, agitada y caótica. Los ángulos agudos y las pinceladas enérgicas de obras como Potsdamer Platz, Berlin (1914) o La roja ribera Elizabeth en
Berlín (1912) dan fe del impacto que supuso en la vida y en la obra de Kirchner su llegada a una ciudad, Berlín, que se presenta ante sus ojos como irreal, enfermiza, inhumana, hostil. ${ }^{36}$

\section{Nueva York, Chicago y las ciudades genéricas}

Aproximadamente en las mismas fechas en que el Expresionismo alemán comenzaba a dar sus primeros pasos, nace en Estados Unidos el departamento de sociología de la universidad de Chicago, creado en 1892 y que tendrá como principal representante a Robert Ezra Park, que se incorporará al mismo en el año 1915. Al grupo de sociólogos y antropólogos que se incorporarán a esta universidad se les conocerá como la Escuela de Chicago, y una de sus principales aportaciones a la antropología será la de hacer girar el objeto de estudio desde las sociedades tribales hacia sí mismo, hacia el interior de una ciudad que está en constante transformación y en la que conviven entre sí diferentes zonas con condiciones sociales y de vida muy distintas, desde barrios muy pobres hasta otros en donde el único protagonista es el lujo de la modernidad. El mismo Simmel fue muy importante para forjar este nuevo campo de estudio antropológico, gracias a unas teorías que hablaban de la ciudad como un lugar repleto de relaciones mercantilizadas y opuesto a las poblaciones rurales. La transición de lo rural a lo urbano, de hecho, fue uno de los principales temas tratados por los antropólogos de la Escuela de Chicago, especialmente por Robert Redfield, discípulo de Radcliffe-Brown, quien apuntó a la existencia de un continuo en cuyos extremos se situaban lo rural -lo folk- y lo urbano, y dentro del cual se ubicaban las distintas ciudades y poblaciones según estuviesen más cerca de un tipo ideal o de otro.

Ese choque entre lo rural y lo urbano se aprecia bien en los trabajos de Grant Wood, ejemplificados en obras como Death on the Ridge Road (1935), Appraisal (1931) ${ }^{37}$ o la archiconocida y satírica American Gothic (1930). El simbolismo de sus cuadros ha propiciado que Wood pueda llegar a ser considerado el pintor por excelencia del American Regionalism y del mundo rural nortea-

\footnotetext{
34 BÁEZ MACÍAS, Eduardo, 2000.

35 CLARKE, Jay A., 2002, p. 32. Traducción propia.

36 Para una aproximación más cercana a la obra de Kirchner, véase SIMMONS, Sherwin, 2000.

37 Para Barbara E. Ladner, esta obra nos muestra claramente el contraste entre dos mundos distintos basados en sistemas de producción diferentes, el folk o tradicional, por una parte, y el urbano, de corte más industrial, por otra, a través de la representación de dos mujeres que visten ropas totalmente distintas, cada una de ellas acorde al mundo en el que viven. Esto, a su vez, ejemplifica las tensiones que se daban entre ambas formas de vida en la sociedad estadounidense durante los años previos a la Segunda Guerra Mundial (LADNER, Barbara E., 2013).
} 
mericano. ${ }^{38}$ Se trata de un mundo cuyas relaciones sociales estaban articuladas en torno al parentesco y a la relación directa entre personas, que en las grandes ciudades se pierden poco a poco. Louis Wirth, sociólogo y antropólogo estadounidense que también formó parte de la Escuela de Chicago, era muy claro con respecto a estos temas: para él, aunque los contactos en las grandes ciudades puedan darse cara a cara, en realidad no son más que contactos "superficiales, impersonales, transitorios y segmentados". ${ }^{39}$ Las uvas de la ira (1939), la novela de John Steinbeck, refleja esa variación en las relaciones, que cambiarán según nos situemos más cerca de lo rural o de lo urbano. Ese choque se puede apreciar con facilidad cuando la familia protagonista de la obra acude a California y se ve obligada a vivir en diferentes campamentos que son como pequeños guetos, lugares marginados en los que, aunque aún se mantengan algunos de los valores propios del mundo rural, estos poco a poco se van perdiendo en pro de unas relaciones cada vez más mercantilizadas y menos personales, más institucionalizadas.

En lo que respecta a la llegada de la modernidad y a la aparición de las metrópolis, a veces el arte se ha limitado más a reflejar los cambios que a criticarlos. Desde el Impresionismo se veía la llegada de la modernidad generalmente con buenos ojos. En las obras de Manet había una cierta actitud crítica, pero esta no era tanto contra la modernidad sino, más bien, contra la hipocresía de la modernidad. La modernidad por sí misma no era algo tan fácilmente criticable: en ella se abrían nuevas posibilidades de libertad para el individuo. El Expresionismo, en cambio, vio en esa modernidad un elemento amenazante para las relaciones sociales, y la actitud crítica de los autores expresionistas no tardó en aparecer. En Estados Unidos, en cambio, la pintura de la época se ocupó más bien de captar situaciones de esas grandes ciudades, lugares y rincones de la misma, en muchas ocasiones rincones más bien ocultos de cara al visitante pero, en cualquier caso, sin tanta actitud crítica como tuvo el movimiento expresionista alemán. La modernidad no solo se había asentado sino que la vida urbana dentro de la metrópolis comenzaba a ser la única realidad po- sible. La actitud crítica, cuando la hubo, se desvió al elemento más puramente social, a las desigualdades existentes entre las clases obreras y las más poderosas. Dentro del arte estadounidense, esta crítica se centró especialmente en las representaciones de las calles de Nueva York, que en aquellos años se transformó, de "una copia barata de la modernidad parisina [...], en la ciudad modernista del siglo XX". ${ }^{40}$ El pintor George Bellows, por ejemplo, supo captar perfectamente no solo el caos de la gran ciudad, sino también la dura forma de vida en unos barrios de clase obrera cada vez más sobrepoblados, gracias, entre otras cosas, al enorme incremento de la inmigración, imagen que se contraponía con la vida de lujo de las gentes de clase alta, más acordes al Gatsby de Scott Fitzgerald. También Jerome Myers, que dedicó la mayor parte de su obra a pintar las barriadas norteamericanas, supo retratar ya a comienzos del siglo XX esas zonas que se iban poblando cada vez más debido a la masiva afluencia de inmigrantes que llegaban a la ciudad.

Pero quizá a la hora de hablar de la representación pictórica de escenas urbanas norteamericanas debemos mencionar antes que a nadie a los artistas de la denominada Escuela Ashcan, que saltaron al primer plano del escenario artístico norteamericano por atreverse a pintar el caos de los barrios y la vida urbana profunda neoyorquina en una época en la que el arte estadounidense estaba dominado casi por completo por el dinero de la aristocracia, fiel a un academicismo de corte más conservador. Avalados por la escultora Gertrude V. Whitney, bien posicionada económicamente, un grupo de artistas, entre los que se encontraban los miembros más característicos de esta escuela y otros como Edward Hopper -también incluido en ocasiones dentro de ella-, decidieron rebelarse contra ese academicismo y comenzar a trasladar al lienzo una serie de escenas que nada tenían que ver con la luminosa felicidad que la academia pretendía mostrar. El ya mencionado Jerome Myers fue uno de esos autores a los que se ha incluido en la Escuela Ashcan. ${ }^{41}$ La calle, que en el París baudeleriano había sido sinónimo de modernidad y progreso, viene ahora a simbolizar "algo sucio, desor-

\footnotetext{
38 Para un análisis detallado de la obra de Wood, véase BAIGELL, Matthew, 1966.

39 WIRTH, Louis, 1988, p. 171.

40 TALLACK, Douglas, 1997, p. 44. Traducción propia. La cursiva es del autor.

${ }^{41}$ Nombre que, en realidad, no fue puesto por sus integrantes, sino que apareció más adelante y se utilizó para denominar a aquel grupo de autores norteamericanos que a comienzos del siglo XX estaban interesados en captar la cotidianidad de la vida urbana en toda su frialdad, a través de la creación de oscuras representaciones pictóricas que pretendían reflejar el caos de las avenidas de la gran ciudad, la aglomeración de los bares, la popularidad del cine, el auge del circo, los espectáculos teatrales, etc.
} 
denado, indolente, estancado, obsoleto: todo lo que, supuestamente, el dinamismo y el progreso de la modernidad dejarían atrás". ${ }^{42}$

Desde la nueva antropología norteamericana comenzó a pensarse la ciudad como si fuese un organismo vivo en el que conviven diferentes individuos, agrupados en comunidades cada una de ellas con su propio funcionamiento y con sus propias formas de interactuar, bien sea en términos de cooperación con los iguales o en términos de competencia con los que son diferentes, aquellos que pertenecen a otro grupo, a otra cultura. Esta teoría recibió el nombre de Ecología Cultural, y fue propuesta por Julian Steward para estudiar cómo el entorno físico de los individuos, así como la influencia de la tecnología, afectan a sus relaciones sociales, las cuales, a su vez, redefinen algunos aspectos de la cultura en la que están inmersos. Eso es precisamente lo que Steward pretendía mostrar: que las culturas son el resultado de procesos concretos de adaptación a unos medios ecológicos determinados. Siguiendo esto, al final la ciudad norteamericana por antonomasia quedaría constituida en un modelo de círculos concéntricos, diferente al de las ciudades europeas, en el que los barrios marginales, generalmente habitados por los inmigrantes, quedarían completamente separados de los barrios que sirven de residencia a los trabajadores locales, situados en un círculo exterior al otro, y que a su vez estaría rodeado de otro círculo en el que se situarían las clases más altas. Así, al final llegaríamos a lo que desde la actual antropología urbana se ha descrito como modelo de urbanismo disperso, alternativa norteamericana a la regularidad cuadriculada europea y que consiste en la construcción de viviendas distantes las unas de las otras, de tal manera que las relaciones interpersonales ya no es que se dificulten ni pasen a ser indirectas, sino que son inexistentes.

John French Sloan y Everett Shinn fueron dos de los representantes de la Escuela Ashcan que plasmarían las nuevas realidades urbanas y cuyo estilo marcaría los primeros pasos para un movimiento que más tarde se denominaría Realismo Americano, dentro del cual se incluiría otro de los miembros de la Escuela Ashcan, Robert Henri, así como el ya mencionado George Bellows. Pero si hay al- guien realmente representativo del Realismo Americano, ese es Edward Hopper. Considerado por el prestigioso magazine Art Digest como "el intérprete más exitoso de la escena americana, en el sentido de que logra obtener la esencia de su tema", ${ }^{43}$ la mayoría de las obras de Hopper pretenden ejemplificar, a través de la representación de diferentes escenas y paisajes neoyorkinos, la alienación que las nuevas formas de vida provocan en los habitantes de las ciudades. ${ }^{44}$ Esta alienación se plasma en obras tales como Manhattan Bridge Loop (1928) o Approaching a City (1946), que muestran la frialdad y falta de personalidad de las grandes urbes, así como en otras como Office in a Small City (1953) o Automat (1927), en las que esa frialdad se traslada a los personajes que las protagonizan. En Nighthawks (1942), quizá su pintura más conocida, se observa una calmada escena de bar cuyo elemento principal es el silencio: los clientes se mantienen absortos en sus pensamientos mientras las calles que rodean al bar permanecen vacías, reflejo de la soledad de la vida en las grandes ciudades, un tema bastante recurrente en la obra de Hopper. Él, al contrario que muchos de sus contemporáneos, no estaba tan interesado en captar el ruidoso bullicio y las aglomeraciones de las ciudades norteamericanas, sino más bien la dramática soledad a la que se encaminaban las almas de sus habitantes, algo que será común a lo largo de toda su obra. ${ }^{45}$ Son lugares que caminan, sin saberlo, hacia la ciudad genérica de Koolhaas.

\section{Reflexiones finales en torno a la ciudad actual}

La reflexión sobre el espacio construido no es nada fácil. Igual que aquí hemos hablado de la ciudad, también podríamos haber ido más allá: hacia las viviendas, hacia los centros de trabajo, hacia los lugares de ocio. Las ciudades son cambiantes, dinámicas, no permanecen nunca estáticas ni sus formas son necesarias, por mucho que las lógicas racionales actuales se nos presenten como tal. En esa fórmula encaja perfectamente la ciudad genérica actual, que es la utopía de las lógicas económicas de la postmodernidad, en la que todo está condicionado por el valor de mercado. No es que todo se convierta en mercancía, sino que todo es ya mercancía. En la utopía capitalista, el ser hu-

\footnotetext{
42 BERMAN, Marshall, 1989, p. 333.

43 Art Digest, 1927, n 1 (marzo), citado en BAIGELL, Matthew, 1968, p. 394. Traducción propia.

44 NOCBLIN, Linda, 1981; SLATER, Tom, 2002; FILIPCEVIC CORDES, Vojislava, 2018.

45 Un repaso bastante más profundo sobre el estilo, las influencias y los temas tratados por Hopper puede encontrarse en BONNEFOY, Yves, 2007.
} 
mano se encuentra desprotegido ante el mundo que le rodea, aunque sin saber que lo está. La ciudad genérica le habrá robado su identidad, se habrá apoderado de ella y nadie habrá salido realmente herido, porque nadie sabrá que le han arrebatado una parte de su ser. Esa vacuidad identitaria es una de las características más esenciales de la ciudad genérica. En ella, la identidad ya no puede abarcar un pasado común compartido, pues cada vez hay menos para compartir. De esa forma la identidad se vacía, y cuanto más vacía esté menos se resiste al cambio. Como apunta Marc Augé, "la sobremodernidad es productora de no lugares, de espacios que no son en sí lugares antropológicos y que, contrariamente a la modernidad baudeleriana, no integran los lugares antiguos". ${ }^{46}$ Muchas de esas ciudades, sin embargo, tratan de aferrarse a una esencia basada muchas veces en el casco histórico de la ciudad, que sin embargo apenas tiene ya fuerza para mantener unidas todas las partes. Muchas ciudades insisten en mantener su esencia a partir del papel histórico de su centro, pero no se dan cuenta de que, al expandirse, esa esencia, lejos de agrandarse, se difumina.

Las ciudades genéricas de Koolhaas son lisas y fractales, construidas como si fuesen bloques, de tal manera que tú puedas cambiar una zona por otra sin notar la diferencia, porque los edificios son similares en todas partes, como en los cuadros de Grosz, como en los de Hopper. Son edificios altos, cada vez más, porque la ciudad genérica tiende a la verticalidad, que es más útil; si no lo fuese, se abandonaría, del mismo modo que se han abandonado partes de su historia por el mero hecho de que carecían de una función concreta. Y es que la historia tampoco importa dentro de la ciudad genérica. Tal como apunta Koolhaas, "todas las ciudades genéricas surgen de la tabla rasa: si no había nada, ahora están ellas; si había algo, lo han reemplazado. Debían hacerlo, de otro modo serían históricas". ${ }^{47}$ Su falta de historia se debe en gran medida a la insustancialidad de sus fundamentos: cualquiera puede fundar una ciudad genérica. El ejemplo más claro es la ciudad de Las Vegas, fundada por el crimen organizado en los años cuarenta a partir de la nada. Otro ejemplo es la ciudad de Shenzhen, en China, que pasó de tener apenas veinticinco mil habitantes en 1980 a los más de diez millones que la pueblan hoy. De aquella pequeña aldea de pescadores ya no queda nada, ni una mínima parte de lo que fue. Son, en el fondo, ciudades del olvido, ciudades en las que cada nuevo día hace olvidar al anterior, ciudades de recuerdos confusos que se difuminan y desaparecen poco después de haberse creado, ciudades de instantes efímeros, de momentos fugaces. Igual que la Berlín de Kracauer.

En esa fugacidad, sin embargo, tiene lugar una de las principales paradojas de la postmodernidad: la nostalgia por el pasado inexistente, materializada, sobre todo, en los procesos de patrimonialización de aquellos elementos que son calificados como símbolos identitarios con la pretensión de que logren abarcar parte de la esencia de la historia de la ciudad. Pero la ciudad genérica, después de borrar su historia, se preocupa por ella, no porque tema perderla, sino porque la historia también puede ser mercantilizada: es lo que se vende a los turistas, que al final acaban viendo en la ciudad genérica lo mismo que en sus ciudades de origen, que también se encaminan al mismo destino, y a las que se vuelven con recuerdos genéricos ocultos tras la falsa apariencia de la distinción.

Dirá el literato Italo Calvino ${ }^{48}$ que a través de lo que la ciudad ha llegado a ser, evocamos con nostalgia aquello que una vez fue. Reclamamos la historia solo después de olvidarla, pero cuando nos damos cuenta de ello el mal ya ha sucedido o es inevitable. La fundamentación de la arquitectura moderna, de la construcción de las metrópolis, ha dado un giro radical, y los principios sobre los que ahora se asientan las nuevas ciudades no dejan ver a las personas que un día las levantaron. "Lo que ha quedado atrás es una tradición difícil de restaurar y que hallaba en los principios del humanismo las referencias programáticas para pensar el proyecto"; 49 hoy ya no se siguen esos principios, sino otros: el principio de utilidad, cuya base ideológica es la de la economía de mercado. Toda ciudad refleja los vestigios de su pasado, su realidad presente y las expectativas futuras. Las ciudades genéricas, sin embargo, tienden poco a poco a olvidar lo primero, y eso las precipita cada vez con más fuerza al abismo de la generalidad, en donde la falta de identidad hace de la vida algo casi banal. Porque aunque lo hayamos olvidado, el hombre es un ser social, y las ciudades tienen su origen precisamente en esa sociabilidad y

\footnotetext{
${ }^{46}$ AUGÉ, Marc, 2005, p. 83.

${ }^{47}$ KOOLHAAS, Rem, 2011, p. 26.

48 CALVINO, Italo, 1994.

49 JARAUTA, Francisco, 2012, p. 73.
} 
en esa comunidad basada en unas relaciones interpersonales cercanas, directas, primarias. Como bien apunta Louis Wirth, "nunca ha estado la humanidad más alejada de la naturaleza orgánica que en las condiciones de vida características de las grandes ciudades". 50

\section{Bibliografía}

AUGÉ, Marc. Los no lugares. Espacios del anonimato. Barcelona: Gedisa, 2005.

BÁEZ MACÍAS, Eduardo. "Otto Dix: serie gráfica sobre la guerra". Anales del Instituto de Investigaciones Estéticas, 2000, n 76, pp. 237-251.

BAHR, Hermann. Expresionismo. Murcia: Arquilectura, 1998.

BAIGELL, Matthew. "Grant Wood Revisited". Art Journal, 1966, vol. 26, $n^{\circ} 2$, pp. 116-122.

BAIGELL, Matthew. "The Beginnings of 'The American Wave' and the Depression". Art Journal, 1968, vol. 27, nº 4, pp. 387-398.

BATAILLE, Georges. Manet. Murcia: Arquilectura, 2003.

BAUDELAIRE, Charles. El pintor de la vida moderna. Murcia: Arquilectura, 1995.

BENJAMIN, Walter. "París, capital del siglo XIX". En Ibid., Poesía y capitalismo. Madrid: Taurus, 1988, pp. 171190.

BERMAN, Marshall. Todo lo sólido se desvanece en el aire: la experiencia de la modernidad. Buenos Aires: Siglo Veintiuno Editores, 1989.

BONNEFOY, Yves. "Edward Hopper: la fotosíntesis del ser". Revisiones, 2007, vol. 3, pp. 153-167.

CALVINO, Italo. Las ciudades invisibles. Madrid: Siruela, 1994.

CLARK, T. J. The painting of modern life. Paris in the art of Manet and his follower. Nueva Jersey: Princeton University Press, 1984

CLARKE, Jay A. "Neo-Idealism, Expressionism, and the Writing of Art History". Art Institute of Chicago Museum Studies, 2002, vol. 28, n 1, pp. 24-37.
FILIPCEVIC CORDES, Vojislava. "The Agitated City: Urban Ambiguity and New York's Noir Metropolis". Quarterly Review of Film and Video, 2018, vol. 35, $n^{\circ} 4$, pp. 1-25.

JARAUTA, Francisco. "Presentación". En BATAILLE, Georges. Manet. Murcia: Arquilectura, 2003.

JARAUTA, Francisco. "Construir la ciudad genérica". DC Papers. Revista de crítica y teoría de la arquitectura, 2012, vol. I, n²3, pp. 69-76.

KOOLHAAS, Rem. La ciudad genérica. Barcelona: Gustavo Gili, 2011.

KRACAUER, Siegfried. Estética sin territorio. Murcia: Arquilectura, 2006

LADNER, Barbara E. "Grant Wood's Appraisal: Where Folk Art and Popular Culture Meet". Encuentros, 2013, n², pp. 37-54.

LESMES GONZÁLEZ, Daniel. "George Grosz y los malos humos de Moloc". Anales de Historia del Arte, 2016, $\mathrm{n}^{\circ} 16, \mathrm{pp} .339-354$

NOCBLIN, Linda. "Edward Hopper and the Imagery of Alienation". Art Journal, 1981, vol. 41, n² 2, pp. 136141.

PIZZA, Antonio; PLA, Maurici. Viena - Berlín. Teoría, arte $y$ arquitectura entre los siglos XIX y XX. Barcelona: Ediciones UPC, 2002.

RANNELLS, Edward W. "Expressionism vs. Impressionism". Design, 1945, vol. 47, n 4, p. 13.

SIMMEL, Georg. El individuo y la libertad. Barcelona: Península, 1986.

SIMMONS, Sherwin. "Ernst Kirchner's Streetwalkers: Art, Luxury, and Immorality in Berlin, 1913-1916". The Art Bulletin, 2000, vol. 82, n 1, pp. 117-148.

SLATER, Tom. "Fear of the city 1882-1967: Edward Hopper and the discourse of anti-urbanism". Social and Cultural Geography, 2002, vol. 3, n 2, pp. 135-154.

SMITH, Paul. Impresionismo. Madrid: Akal, 2006.

TALLACK, Douglas. "New York, New York". Renaissance and Modern Studies, 1997, vol. 40, n 1, pp. 42-58.

WIRTH, Louis. "El urbanismo como modo de vida". En: BASSOLS, Mario et al. (comp.). Antología de sociología urbana. México: Universidad Nacional Autónoma de México, 1988, pp. 162-182. 
